\title{
Thermal, Electrical and Mechanical Properties of Ultra-high Molecular Weight Polypropylene and Carbon Filler Composites
}

\author{
Xiaowen JiAng, Yuezhen Bin, Noriko Kikyotani, and Masaru MatsuO ${ }^{\dagger}$ \\ Department of Clothing Environment, Faculty of Human Life Environment, \\ Nara Women's University, Kitauoyanishi-machi, Nara 630-8263, Japan
}

(Received August 22, 2005; Accepted December 26, 2005; Published May 15, 2006)

\begin{abstract}
Isotactic ultra-high molecule weight polypropylene (UHMWPP) composites filled with multi-wall carbon nanotubes (MWNTs), vapor growth carbon fibers (VGCFs) and short carbon fibers (CFs) were prepared by gelation/crystallization from solutions, in which these aspect ratios of MWNTs, VGCFs and CFs chosen were 5001000, 50-300 and 5-20, respectively. The thermal, electrical and mechanical properties of these composites were studied in terms of their aspect ratios of the three kinds of fillers. The admixture of the three kinds of carbon filler provided better improvement of thermal property in comparison with neat UHMWPP, and the effect was the most significant for the admixture of MWNTs with the highest average aspect ratio. The electrical conductivity by the admixture of carbon fillers was also sensitive to the aspect ratio. Namely, the electrical conductivity of undrawn UHMWPP-MWNT composite film was the highest, when the filler content of the composites was the same. The conductivities of UHMWPPVGCF and UHMWPP-CF composites decreased drastically by elongation up to 5 times $(\lambda=5)$, while the conductivity of UHMWPP-MWNT maintained $c a \cdot 10^{-3} \mathrm{~S} / \mathrm{cm}$ at $\lambda=5$ but further elongation up to $\lambda=20$ caused a gradual decrease of the conductivity. Young's modulus of the UHMWPP-VGCF composites was higher than that of neat UHMWPP films in undrawn and drawn states, while that of UHMWPP-MWNT composites became lower when the composite with $3 \mathrm{wt} \%$ MWNT content was elongated up to $\lambda=20$. These phenomena indicated that a number of entanglement points of MWNTs within the composite assure electric channels in drawn state but hamper the smooth orientation of UHMWPP chains. [doi:10.1295/polymj.38.419]

KEY WORDS Ultra-high Molecular Weight Polypropylene / Multi-wall Carbon Nanotubes / Vapor Growth Carbon Fibers / Carbon Fibers / Gelation/Crystallization / Entanglement Points /
\end{abstract}

Thermoplastic polymers are well-known as materials that can be easily molded by different conditions to control the morphology in order to improve mechanical properties and other physical properties. The most common approach to prepare the materials with good mechanical properties and high electrical conductivity is to admix highly conductive fillers, such as carbon black, chopped carbon fibers or metal particles, into polymers. The mechanical property of the blend film is more pronounced in comparison with the neat crystalline polymer. ${ }^{1,2}$ Certainly, the above fillers are conductive particles and then the resultant composite materials have possibilities to provide lightweight, readily moldable, and conductive characteristics.

Among thermoplastic polymers, isotactic polypropylene (it-PP) has many advantages as a matrix resin to produce thermoplastic composites owing to its relatively low cost, low density and high chemical resistance coupled with ease of fabrication. A major limitation of it-PP is due to the fact that its glass transition is lower than room temperature; consequently its dimensional stability is limited. ${ }^{3}$

Carbon nanotubes (CNTs) have attracted considera- ble attention from polymer scientists. Due to their low density and their high aspect ratio represented as average length/average diameter of fillers, they may be used as substitutes for traditional fibers as fillers in polymer matrices. Depending on the synthesis conditions, nanotubes take multi-walled $(2-50 \mathrm{~nm})$ or single-walled $(\sim 1 \mathrm{~nm})$ structures. Multi-wall carbon nanotubes (MWNTs) are much cheaper than that of single-wall carbon nanotubes (SWNTs) and they have good intrinsic mechanical properties with tensile modulus $\sim 1 \mathrm{TPa}$, compressive strength $\sim 150 \mathrm{GPa}$ and tensile strength $\sim 63 \mathrm{GPa}$. Such characteristics are very attractive for utilizing as fillers of nano-composites. ${ }^{4}$

Carbon fibers are widely used as fillers in composite materials, particularly lightweight polymer-matrix composites. The conventional carbon fibers (typical diameter ranging from 7 to $15 \mu \mathrm{m}$ ) are made by pyrolysis from pitch and polymers. ${ }^{5}$ Vapor grown carbon fibers (VGCFs) are a relatively new type of carbon fiber which is produced from the pyrolysis of a hydrocarbon gas, such as benzene and methane, in the presence of hydrogen at temperatures around 950-1200 ${ }^{\circ} \mathrm{C}$. Depending on the preparation conditions, VGCFs

${ }^{\dagger}$ To whom correspondence should be addressed (Tel/Fax: +81-742-20-3462, E-mail: m-matsuo@cc.nara-wu.ac.jp). 
can be made with diameters between several tens of nanometers up to tens of microns and length from several microns up to many centimeters. ${ }^{6-11}$ Of course, the morphology of VGCFs is similar to that of MWNTs.

It is well-known that the mechanical properties of crystalline polymer are affected by the admixture of fillers, which is attributed to the kinetics of the crystallization. So the investigations have been focused on the kinetics of crystallization of isotactic low molecular weight PP (it-LMWPP) under nonisothermal conditions as a function of the cooling rate under the presence or absence of CNTs. According to Avrami's theory concerning the nucleation activity, the DSC isothermal curves suggested that the carbon nanotubes acted as nucleating agents for it-PP. ${ }^{12}$ Following Assouline et al., it may be expected that the MWNTs act as $\alpha$-nucleating agents of ultra-high molecule weight polypropylene (UHMWPP), and the novel morphology was observed instead of the usual spherulites. $^{4}$

SWNTs and MWNTs, and carbon fibers (CFs) are known as reinforce fillers associated with the improvement of mechanical properties of composite materials. It has been reported for pitch/SWNT, ${ }^{13} \mathrm{PP} /$ VGCF, ${ }^{14}$ polystyrene/MWNT, ${ }^{15}$ poly(vinyl alcohol) (PVA)/MWNT, ${ }^{16}$ poly(methyl methacrylate) (PMMA)/ SWNT, ${ }^{17}$ poly(hydroxyl-aminoether) (PHAE)/ MWNT, ${ }^{18} \mathrm{PP} / \mathrm{MWNT}^{19}$ and PP/SWNT. ${ }^{20}$ Amash et $a l$. investigated the dynamic mechanical thermo-analysis (DMTA) behavior of it-PP and reactor blend of it$\mathrm{PP} /$ ethylene-propylene copolymer (EPM), reinforced with different amounts of short glass fibers (GF) and/or polyester fibers (PETF), which indicated an increase in the stiffness and a decrease of the damping with increasing GF content. ${ }^{21}$ The adhesion of PETF into it-PP enhanced its damping values at low temperatures and promoted the $\alpha$-transition. Recently, Manchado et al. ${ }^{22}$ reported that in the tensile mechanical properties test, Young's modulus and tensile strength considerably increase in the presence of SWNTs, with a maxmum for $0.75 \mathrm{wt} \%$, and also in the dynamic mechanical analysis, the storage modulus have a noticeable increase by admixing SWNTs.

This paper deals with the mechanical property and electric conductivity of composite materials of isotactic ultra-high molecular weight polypropylene (UHMWPP) by using three kinds of filler, MWNTs, VGCFs, and CFs with different aspect ratios. The composite materials were prepared by gelation/crystallization from dilute solutions, ${ }^{23,24}$ since the admixture of it-UHMWPP and carbon fillers are impossible by kneading methods at melt state of UHMWPP because of high viscosity of melted UHMWPP. The characteristics of the composites are focused on the formation of entanglement points associated with flexibility of the carbon fillers as well as on an advantage to use UHMWPP with higher viscosity and melting point than it-LMWPP.

\section{EXPERIMENTAL}

Three kinds of carbon fiber with typically different shapes and different aspect ratios were used in the present work. The photos of these fillers by scanning electron microscopy (SEM) were shown in Figure 1, and the characteristics are listed in Table I. SEM micrographs were observed by JSM-T300 (JEOL Datum Ltd.) and FESEM JSM-6700FN (JEOL Datum Ltd.). To observe the cross-section of the composite film,

Table I. Characterization of the three kinds of filler

\begin{tabular}{lccc}
\hline \multicolumn{1}{c}{ Filler } & Average Diameter & Length $(\mu \mathrm{m})$ & Aspect ratio \\
\hline MWNT & $20 \mathrm{~nm}$ & $10-20$ & $500-1000$ \\
VGCF & $150 \mathrm{~nm}$ & $10-50$ & $50-300$ \\
CF & $4.5 \mu \mathrm{m}$ & $20-100$ & $5-20$ \\
\hline
\end{tabular}

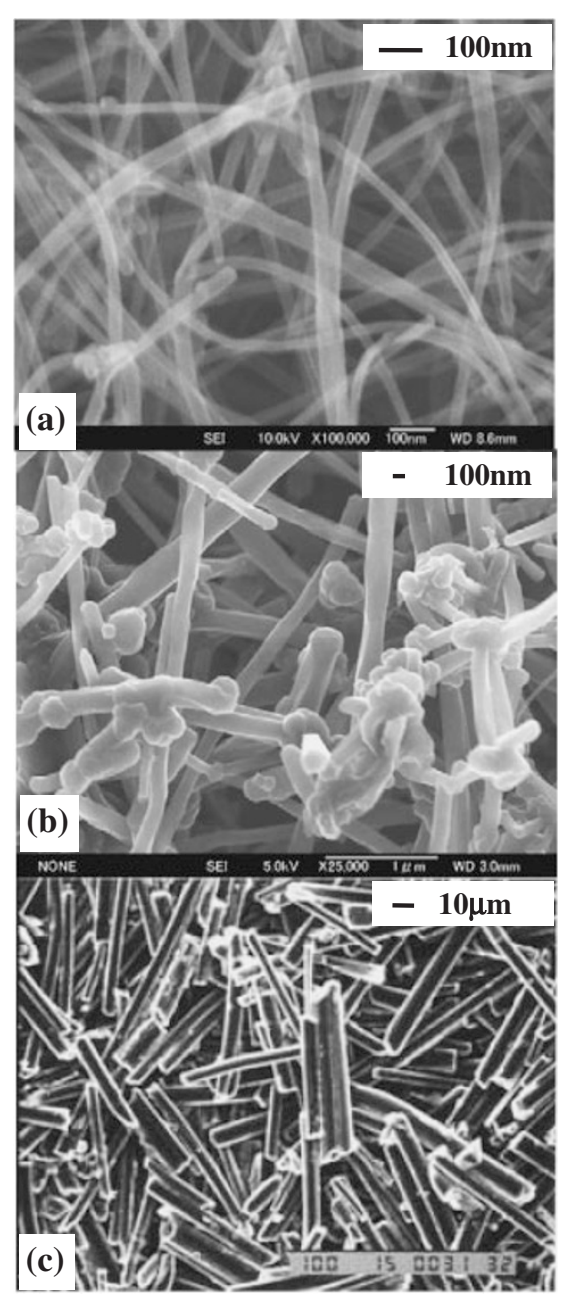

Figure 1. SEM micrographs of three kinds of fillers: (a) MWNTs, (b) VGCFs and (c) CFs. 
the film was put into liquid nitrogen and the frozen film was cracked by hands. The detailed observation of SEM reveals that MWNTs have the smaller diameter and the wider diameter distribution in comparison with other two. The MWNTs tend to form bundles of nanotubes like as SWNTs reported already. ${ }^{25,26}$ Photo (b) shows the VGCFs with bigger average diameter and more uniform distribution. Photo (c) shows the CFs with different morphology from MWNTs and VGCFs. The CFs have average diameter of $4.5 \mu \mathrm{m}$ but the average aspect ratio is the smallest among the three.

UHMWPP $\left(M_{v}=5.4 \times 10^{6}\right)$ supplied by Mitsui Chemical Inc. was used in this work. Composite films were prepared by crystallization from solutions and by drying. A decalin (mixture of cis-, trans-isomer bought from Wako Pure Chemical Industries Ltd.) solution containing $5 \mathrm{~g} / 100 \mathrm{~mL}$ UHMWPP and $0.1 \% \mathrm{w} / \mathrm{w}$ the antioxidant di-t-butyl- $p$-cresol against the amount of UHMWPP and carbon fibers were prepared by heating the well-blended polymer/solvent mixture at $150{ }^{\circ} \mathrm{C}$ for $40 \mathrm{~min}$ under nitrogen. The hot homogenized solution was quenched by pouring it into a glass schale surrounded by water at $25^{\circ} \mathrm{C}$ at room temperature, thus generating a gel. The solution thickness was controlled to obtain the films with almost the same thickness $(c a .500 \mu \mathrm{m})$. The solvent was allowed to evaporate from the gel under ambient conditions. The nearly dry gels were put in hotplate about $40-50{ }^{\circ} \mathrm{C}$ for a few days to remove residual traces of decalin. The composite films were drawn at $160^{\circ} \mathrm{C}$ up to desired draw ratios.

Before studying the characteristics of the composites, as a preliminary experiment, the morphology of UHMWPP was observed by SEM and optical microscopy. The optical micrograph was observed by Nikon optical pol. (XTP-11).

Figure 2 shows optical micrographs of the UHMWPP dry gel film under cross-polarization condition. The thin film was prepared to obtain clear focus under the observation. The morphology showed spherulitic textures composed of radial arrangement of lamellae from the center, which provides positive birefringence showing an indistinct black Maltese cross. These indistinct structures as characteristics of UHMWPP are probably two-dimensional spherulites.

Figure 3 shows the SEM images of UHMWPP powders and the gel films treated with the indicated conditions in order to make clear the characteristics. Photo (a) shows that UHMWPP powders are compounded of grains with wide size distribution. The corresponding optical micrograph could not recognize the optical structure of the grains because of the difficulty in fitting the focus. Photo (b) shows the uniform spherulites within the dry gel film. The corresponding

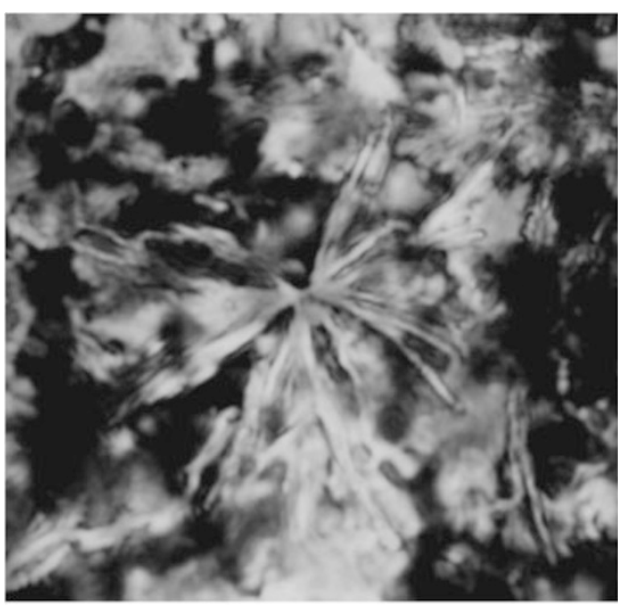

Figure 2. Optical micrograph (crossed polarization) observed for UHMWPP dry gel film, in which polarizer and analyzer were set in the vertical and horizontal direction on this paper.

polarized micrograph suggests the optical anisotropy of the three-dimensional spherulites but the clear structures were indistinct, because the observation sizes were very small. Even so, judging from the appearance of spherulites by gelation/crystallization as shown in Figure 2, it may be expected that the spherulites correspond to three dimensional spherulitic textures with optical anisotropy, indicating ordered aggregation of crystallites and they were formed by the reorganization or recrystallization under the preparation of gel film from the powders. Photo (c) shows the morphology of the film pressed under $9.81 \mathrm{MPa}$ at $70^{\circ} \mathrm{C}$ much lower than its melting temperature. Crushed spherulites are observed. The compression was done to prepare thin and uniform films. On the other hand, photo (d) shows the morphology of the gel film pressed under $3.92 \mathrm{MPa}$ at $140^{\circ} \mathrm{C}$, which is ca. $30^{\circ} \mathrm{C}$ lower than the melting point. The spherulitic textures were also collapsed. The film surface of the film becomes macroscopically smoother in comparison with the compression under $9.81 \mathrm{MPa}$ at $70^{\circ} \mathrm{C}$ and then the films pressed under $3.92 \mathrm{MPa}$ at $140^{\circ} \mathrm{C}$ were adopted mainly as test specimens to estimate mechanical and electric properties.

Thermal weight loss of the specimens under heating process by thermogravimetry (TG) were carried out using TG/DAT 6300 (SII EXSTAR 6000 of Seiko Instrument) at a heating rate of $10^{\circ} \mathrm{C} / \mathrm{min}$ in an $\mathrm{N}_{2}$ atmosphere.

Electric conductivity of the drawn films was measured in the stretching direction by using a two-terminal method at room temperature. To prepare test specimens, the composite material was cut into strips of length $25 \mathrm{~mm}$ and width $15 \mathrm{~mm}$. Before the measurement, the specimen was polished by sandpaper to level off the both sides smoothly and it was clamped 


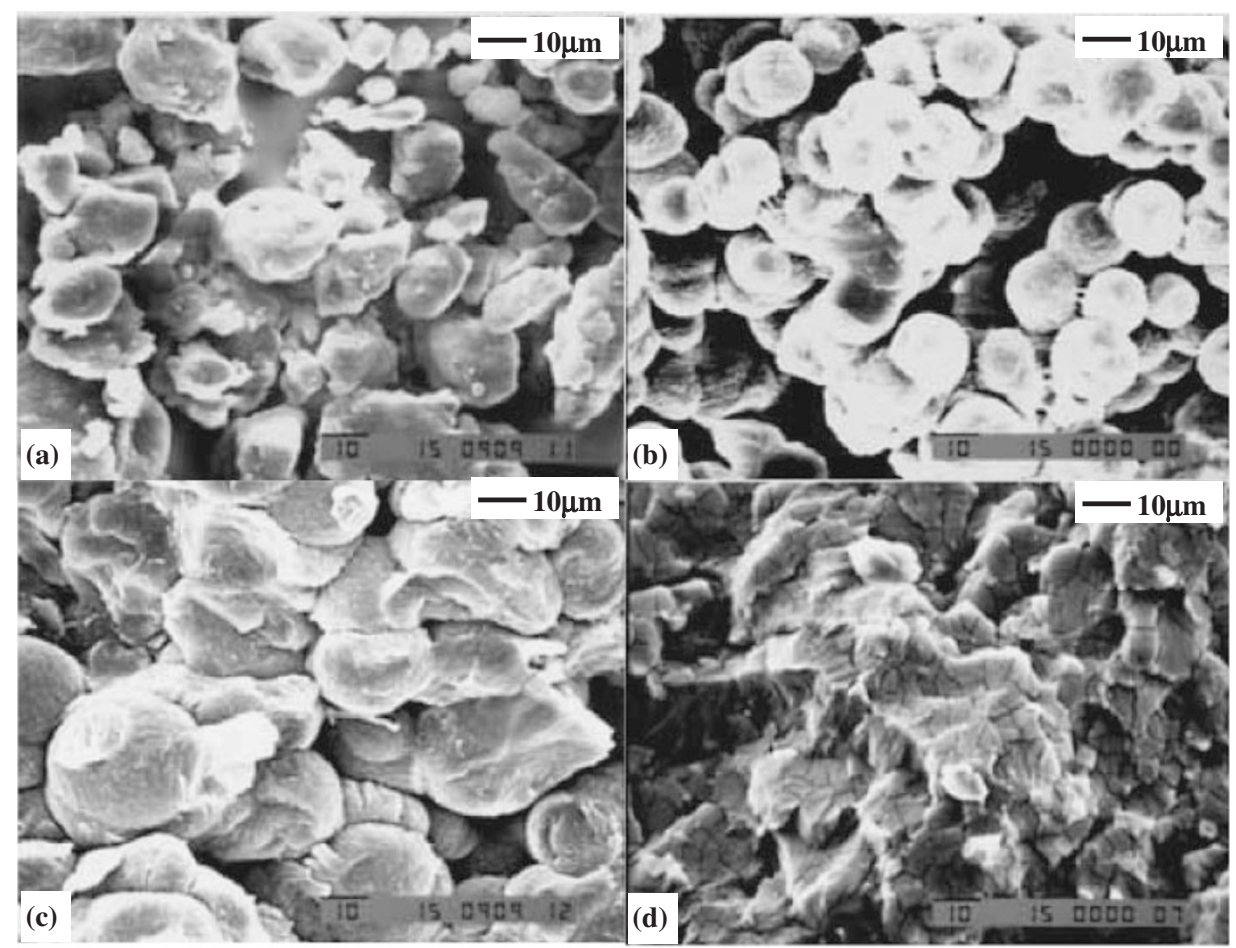

Figure 3. SEM micrographs of neat UHMWPP powder and films prepared by different press conditions: (a) powder, (b) original film (c) film pressed under $3.92 \mathrm{MPa}$ at $70^{\circ} \mathrm{C}$, (d) film pressed at $140{ }^{\circ} \mathrm{C}$.

between copper metal jaws, in which silver paste was used to ensure complete contact between film surfaces and copper jaws. The specimens of electric conductivity $<10^{-6} \mathrm{~S} / \mathrm{cm}$ were measured with the Hewlett 4339B (Hewlett Packard Ltd. Co., Japan) by applying $10 \mathrm{~V}_{\mathrm{DC}}$ of voltage, while the conductivity $>$ $10^{-6} \mathrm{~S} / \mathrm{cm}$ were measured under the constant current of $0.1-1 \mathrm{~mA}$ by the Advantest R6441A Digital Multimeter furnished by Advantest Ltd. Co., Japan. Moreover, precise measurement by a four-terminal method was carried out for specimens with electric conductivity $>10^{-6} \mathrm{~S} / \mathrm{cm}$. The conductivity was calculated by measuring the voltage yield when a constant current of $1 \mathrm{~mA}$ to $100 \mathrm{nA}$ was applied.

The heat of fusion of the specimens was estimated by differential scanning calorimetry (DSC), (DSC 6200, SII EXSTAR 6000 of Seiko Instrument). All measurements were carried out in $\mathrm{N}_{2}$ atmosphere. Based on the DSC curves, the thermal parameters of the crystallization temperature $\left(T_{\mathrm{c}}\right)$, melting temperature $\left(T_{\mathrm{m}}\right)$, crystallization enthalpy $\left(\Delta H_{\mathrm{c}}\right)$, heat of fusion $\left(\Delta H_{\mathrm{f}}\right)$ and percentage of crystallinity $\left(\chi_{\mathrm{c}}\right)$, were obtained. The relative degree of crystallinity was determined from the endothermic peak area of DSC curves by using the following relationship:

$$
\chi_{\mathrm{c}}=\frac{\Delta H_{\mathrm{f}}}{\Delta H_{\mathrm{f}}^{0}} \times 100 \%
$$

A value of $\Delta H_{\mathrm{f}}^{0}, 190 \mathrm{~J} / \mathrm{g}$, was taken for $100 \%$ crystalline PP homopolymer. ${ }^{21}$
WAXD measurements were carried out by a $12 \mathrm{~kW}$ rotating anode $\mathrm{X}$-ray generator with the monochromatic $\mathrm{CuK} \alpha$ radiation (Rigaku RDA-rA operated at $150 \mathrm{~mA}$ and $40 \mathrm{kV}$ ). Corrections of X-ray diffraction intensity were made for air scattering, polarization and absorption.

The dynamic mechanical properties were measured with a viscoelastic spectrometer (VES-F) of Iwamoto Machine Co. Ltd. at a fixed frequency of $10 \mathrm{~Hz}$ over the temperature range from -150 to $180^{\circ} \mathrm{C}$ at a heating rate of $2{ }^{\circ} \mathrm{C} / \mathrm{min}$.

Young's modulus was measured with Instron TENSILON/STM-H-500BP at a speed of $2 \mathrm{~mm} / \mathrm{min}$ at room temperature. The size of the specimens was $40 \mathrm{~mm}$ in length and $2 \mathrm{~mm}$ in width.

\section{RESULTS AND DISCUSSION}

\section{Morphology of the Composites}

Figures $4 \mathrm{a}$ and $4 \mathrm{~b}$ shows SEM micrographs of cross section area of the UHMWPP-VGCF composites with 5 and $10 \mathrm{wt} \%$ VGCF contents, respectively. In photos (a) and (b), the average diameter of spherulites within UHMWPP-VGCF composites before compression was $c a .4 \mu \mathrm{m}$ smaller than $c a .10 \mu \mathrm{m}$ of neat UHMWPP (see Figure 3b). The difference is thought to be due to thermal crystallization modes of UHMWPP under the presence of VGCFs. The photos (c) and (d) show the composites with 5 and $10 \mathrm{wt} \%$ VGCF contents, respectively, after the compression. 


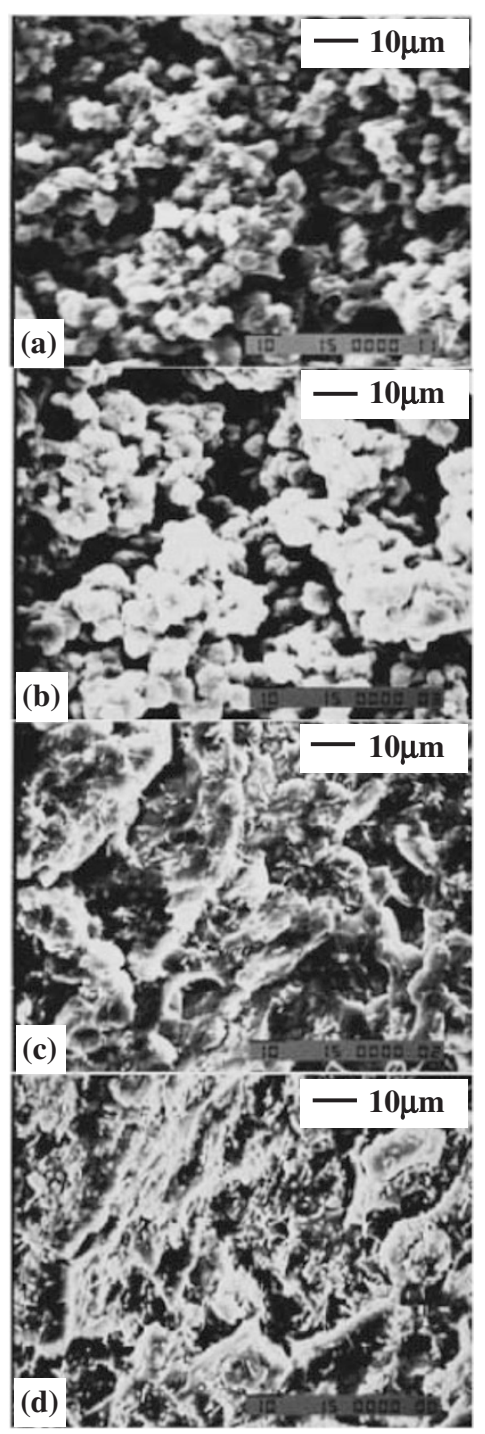

Figure 4. SEM micrographs of the cross-section of the UHMWPP-VGCF composites (a) $5 \mathrm{wt} \%$ and (b) $10 \mathrm{wt} \%$ contents before compression, while with (c) $5 \mathrm{wt} \%$ and (d) $10 \mathrm{wt} \%$ contents after the compression at $140^{\circ} \mathrm{C}$.

Judging from photos (c) and (d) in Figure 4, it is seen that collapse of the spherulites and the appearance of fibrous textures were confirmed in the films pressed under $3.92 \mathrm{MPa}$ at $140{ }^{\circ} \mathrm{C}$. This tendency is more considerable for the $10 \mathrm{wt} \%$ film rather than $5 \mathrm{wt} \%$ film. By the compression, the film surface became flat. The same tendency was confirmed for the MWNT blend and the $\mathrm{CF}$ blend films.

Figure 5 shows SEM photographs of the cross-section area of the UHMWPP-CF films pressed under 3.92 $\mathrm{MPa}$ at $140{ }^{\circ} \mathrm{C}$, in which photos (a) and (b) correspond to the composites with 5 and $10 \mathrm{wt} \% \mathrm{CF}$ contents, respectively. CFs were dispersed in the matrix without forming entanglement points because of the large size of the diameter of CFs. The appearance of fibrous textures by collapse of the spherulites was also observed as in the case of the VGCFs.

SEM photographs of UHMWPP-MWNT composite films are shown in Figure 6, in which photos (a), (b) and (c) correspond to 1, 3 and $5 \mathrm{wt} \%$ MWNT contents, respectively. Because of their thinner diameter and high aspect ratios, entanglement points of MWNTs are observed clearly. The points cause significant effect on the mechanical and electrical properties of the composite films, which shall be discussed later.

\section{X-Ray Diffraction}

Figures 7a, 7b and 7c shows the WAXD intensity distribution curves (through view) from UHMWPPVGCF, UHMWPP-CF and UHMEPP-MWNT composite films, respectively at $25^{\circ} \mathrm{C}$. The thicknesses of all the test films were almost the same. Judging from the profile of neat UHMWPP film $(0 \mathrm{wt} \%)$, the crystal form of UHMWPP is $\alpha$-form and the diffraction peak positions are assigned on the basis of the reference by Natta et al. ${ }^{27,28}$ The diffraction peaks of the (040) and (131) planes are usually higher than those of the (110) and (130) planes. The magnitudes of the diffraction peaks for all the specimens are more intense with increasing the filler content. The curves indicated that admixture of three kinds of filler improve crystallization of UHMWPP. The increase in peak magnitude from the (110) plane was the most noticeable indicating the most significant growth of the crystallites

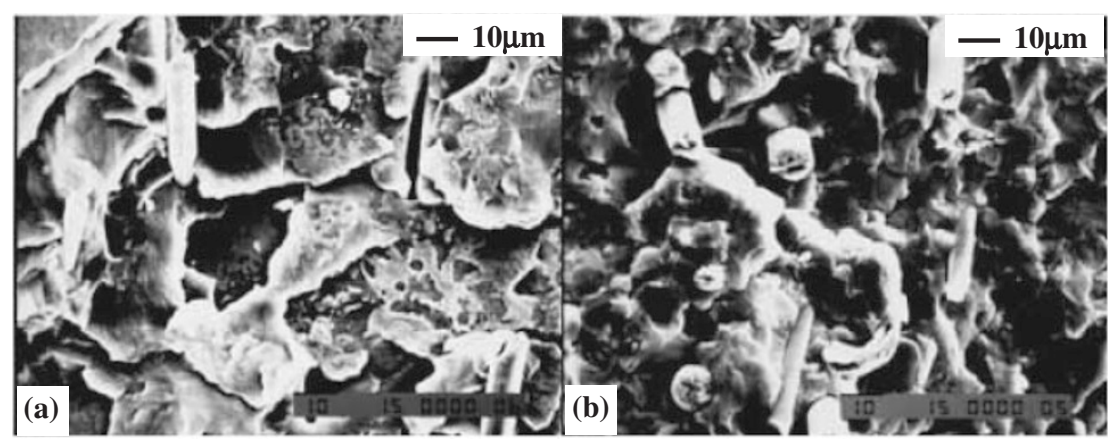

Figure 5. SEM micrographs of the cross-section of the UHMWPP-CF composites (a) $5 \mathrm{wt} \%$ and (b) $10 \mathrm{wt} \%$ contents after the compression. 

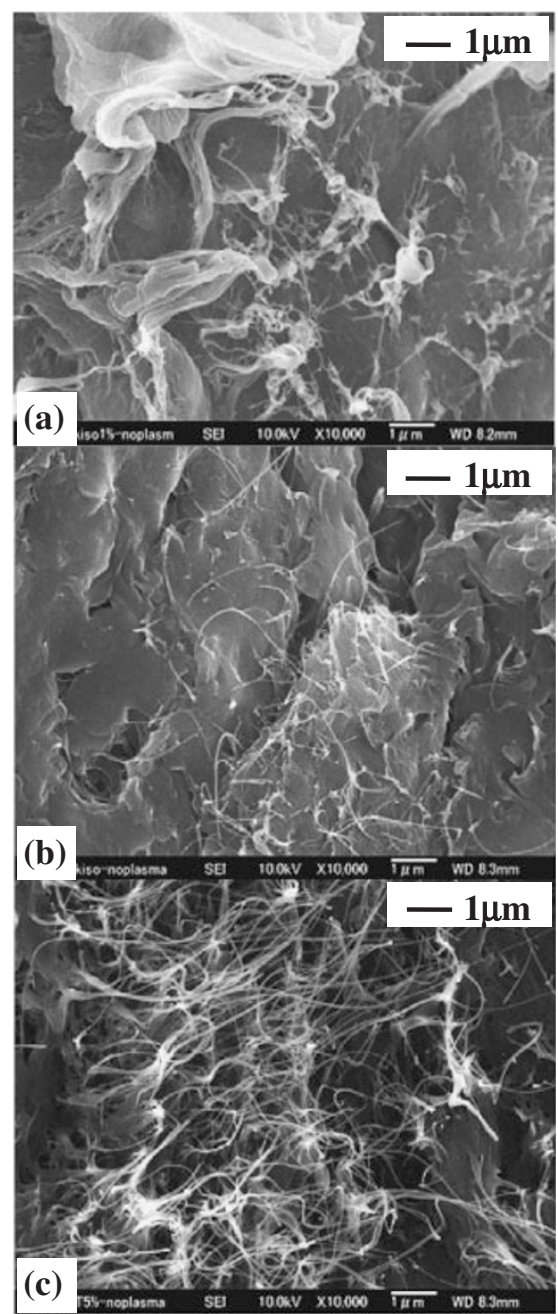

Figure 6. SEM micrographs of cross-section of the pressed UHMWPP-MWNT composites with (a) $1 \mathrm{wt} \%$, (b) $3 \mathrm{wt} \%$ and (c) $5 \mathrm{wt} \%$ contents.

along the [110] direction. Judging from a crystallographic unit cell by Natta et al. ${ }^{27,28}$ this phenomenon is in good agreement with the established results that the longitudinal direction of the lamella is parallel to the [100] direction ${ }^{29,30}$ and the growth of crystal lamellae enhance along the [100] direction. Especially, in Figure $7 \mathrm{c}$, the drastic increase in the diffraction peak magnitude of the (110) plane can be observed clearly even by admixture of only $1 \mathrm{wt} \%$ MWNTs. This means that the crystallization was promoted by admixing small amounts of MWNTs with the highest aspect ratio. Returning to Figure 4, it is seen that the fibrous tissues in the pressed UHMWPP-VGCF composite are finer in comparison with the tissue in neat UHMWPP films and this tendency is more considerable with increasing VGCF content. The same tendency was also confirmed for UHMWPP-CF composite (see Figure 5), indicating that the formation of finer tissues provides an increase in crystallinity.

Figures $8 \mathrm{a}$ and $8 \mathrm{~b}$ shows temperature dependence of X-ray diffraction curves for UHMWPP films and
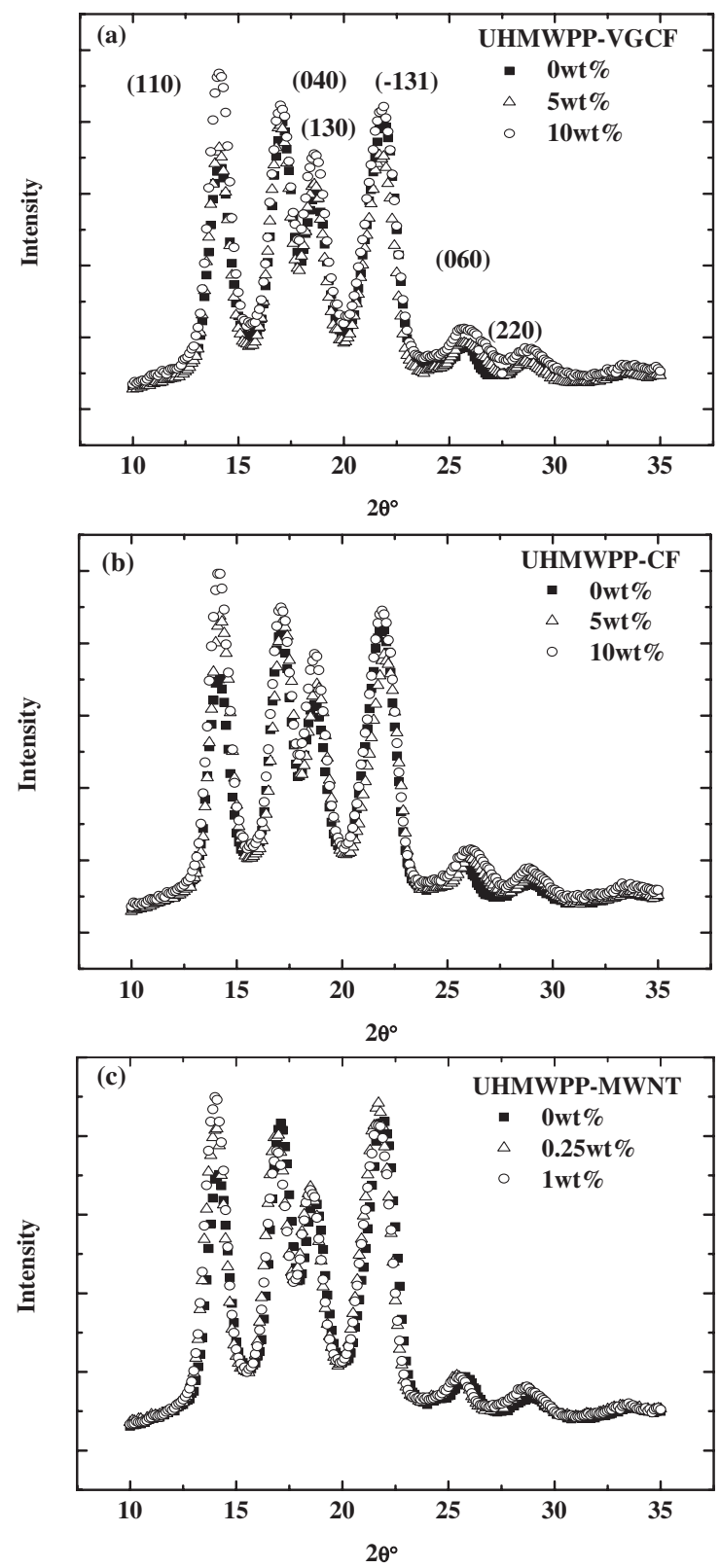

Figure 7. X-Ray diffraction intensity curves of the composites with the indicated filler contents. (a) UHMWPP-VGCF, (b) UHMWPP-CF, (c) UHMWPP-MWNT.

the composite containing $10 \mathrm{wt} \% \mathrm{VGCF}$, respectively. The magnitude of the four diffraction peaks from the UHMWPP film became higher with increasing temperature up to $165^{\circ} \mathrm{C}$ but the peaks decreased at $180^{\circ} \mathrm{C}$ indicating partial melt of the crystallites. The same tendency was confirmed for the composite except the (131) plane showing the decrease of the magnitude with increasing temperature. Interestingly, the decrease for the composite at $180^{\circ} \mathrm{C}$ was more considerable than that for the UHMWPP. Especially the drastic decrease of the (131) plane for the composite was observed. Anyway, it is obvious that the crystallization mechanism of UHMWPP provided different thermal modes by the admixture of VGCFs. This 

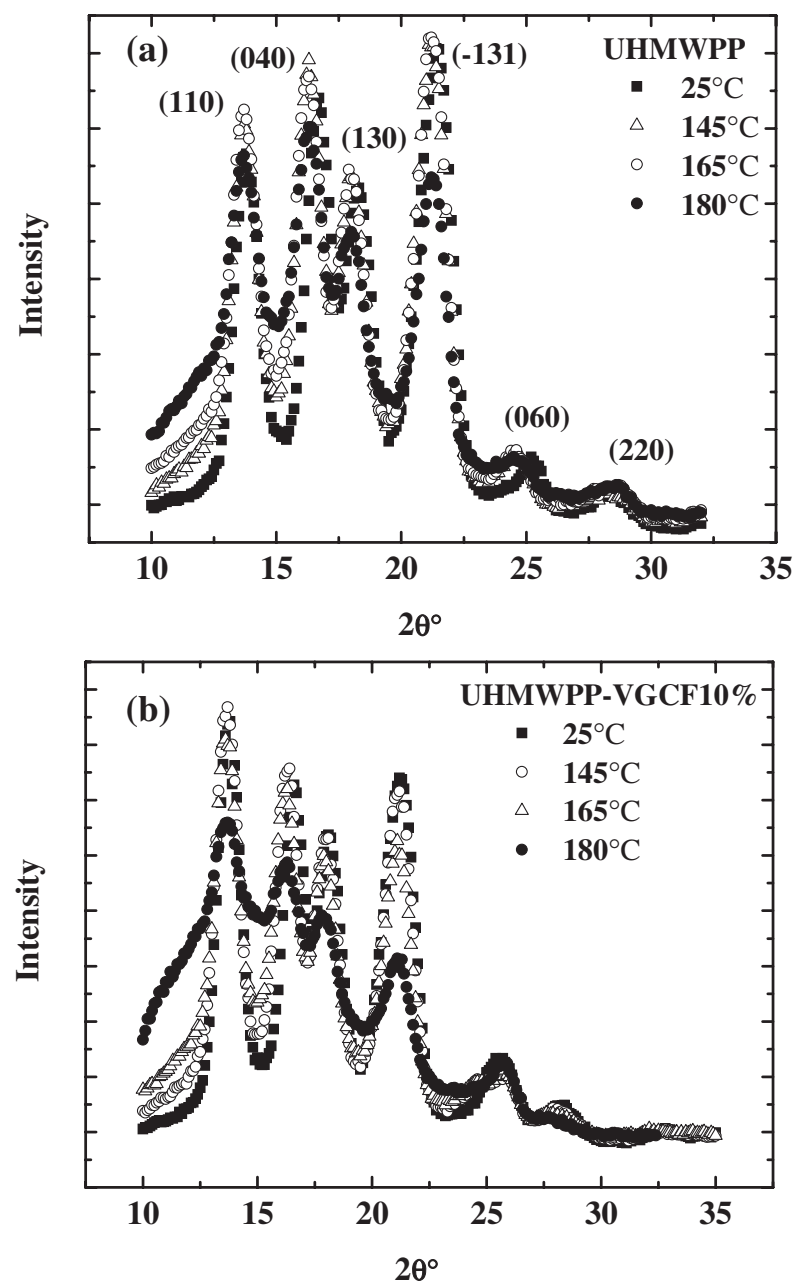

Figure 8. Temperature dependence of X-ray diffraction intensity curves measured for UHMWPP and the composites containing $10 \%$ VGCF. (a) UHMWPP film, (b) composite with $10 \mathrm{wt} \%$ MWNT content.

mechanism remains unresolved problems and further analysis must be taken into consideration.

\section{Mechanical Properties}

The dynamic mechanical properties for the UHMWPP, UHMWPP-MWNT, UHMWPP-VGCF and UHMWPP-CF composites are shown in Figure 9, in which storage modulus $\mathrm{E}^{\prime}$ and loss modulus $\mathrm{E}^{\prime \prime}$ were measured as a function of temperature. It is clear that when $5 \mathrm{wt} \%$ MWNT, VGCF and CF fillers were admixed into UHMWPP, $\mathrm{E}^{\prime}$ of the composite is higher than that of the neat UHMWPP film because of their stiffness. The admixture effect is more pronounced at the low temperature side $<-25^{\circ} \mathrm{C}$.

The admixture effect is the most significant for MWNTs. Namely, the addition of $1 \mathrm{wt} \%$ MWNTs provided an increase in $\mathrm{E}^{\prime}$. But, as a common factor for the three kinds of filler, the further admixture beyond $5 \mathrm{wt} \%$ is no better influence on an increase in $\mathrm{E}^{\prime}$. Namely, $\mathrm{E}^{\prime}$ for the $5 \mathrm{wt} \% \mathrm{VGCF}$ content is higher than that for the $10 \mathrm{wt} \%$ content. Such reverse rela- tionship was also reported by López Manchado et $a l$. for the incorporation of SWNTs in the temperature range from -40 to $100{ }^{\circ} \mathrm{C}^{22}$ The value of $\mathrm{E}^{\prime}$ for the $5 \% \mathrm{wt}$ is almost equal to that for the $10 \mathrm{wt} \%$ for the UHMWPP-CF composites. The same tendency was observed for 3 and $5 \mathrm{wt} \%$ contents for UHMWPPMWNT composites.

As for the $\mathrm{E}^{\prime \prime}$ curves, there exist three relaxtion peaks ${ }^{21,31}$ belonging to mechanical dispersions of the UHMWPP. The $\gamma$-peak appeared at lowest temperature side is associated with the relaxing unit consisting of a few chain segments in the amorphous regions. The $\beta$-peak corresponds to the mobility of the amorphous chain segments and the temperature of the peak maximum is designed as the glass transition temperature $\left(T_{\mathrm{g}}\right)$. The $\alpha$-peak is thought to be the crystal dispersion associated with the grain boundary phenomenon or torsional rotation of the chain axis within the crystallites. The thermal behavior of $\mathrm{E}^{\prime \prime}$ is very complicated and the filler effect cannot be analyzed on the basis of the present results.

By the tensile test, Young's modulus was measured for UHMWPP-VGCF and UHMWPP-MWNT composites. Table II lists the results. The Young's modu-

Table II. Young's modulus of UHMWPP-VGCF and UHMWPP-MWNT measured at room temperature

\begin{tabular}{|c|c|c|c|}
\hline Sample & $\begin{array}{c}\text { Filler } \\
\text { content } \\
(\mathrm{wt} \%)\end{array}$ & $\begin{array}{l}\text { Draw } \\
\text { ratio }\end{array}$ & $\begin{array}{c}\text { Young's } \\
\text { modulus } \\
(\mathrm{GPa})\end{array}$ \\
\hline \multirow[t]{4}{*}{ UHMWPP } & \multirow[t]{4}{*}{0} & 1 & 1.59 \\
\hline & & 10 & 4.64 \\
\hline & & 20 & 9.80 \\
\hline & & 30 & 10.20 \\
\hline \multirow[t]{9}{*}{ UHMWPP-VGCF } & \multirow[t]{4}{*}{5} & 1 & 1.86 \\
\hline & & 10 & 5.70 \\
\hline & & 20 & 8.20 \\
\hline & & 30 & 12.00 \\
\hline & \multirow[t]{4}{*}{10} & 1 & 2.00 \\
\hline & & 10 & 4.76 \\
\hline & & 20 & 11.60 \\
\hline & & 30 & 13.30 \\
\hline & 15 & 1 & 2.01 \\
\hline \multirow[t]{12}{*}{ UHMWPP-MWNT } & \multirow[t]{3}{*}{0.5} & 1 & 1.74 \\
\hline & & 10 & 4.72 \\
\hline & & 30 & 10.70 \\
\hline & \multirow[t]{4}{*}{1} & 1 & 1.97 \\
\hline & & 10 & 5.11 \\
\hline & & 20 & 10.00 \\
\hline & & 35 & 11.70 \\
\hline & \multirow[t]{4}{*}{3} & 1 & 2.04 \\
\hline & & 10 & 4.95 \\
\hline & & 20 & 7.93 \\
\hline & & 25 & 9.30 \\
\hline & 5 & 1 & 1.97 \\
\hline
\end{tabular}


(a)

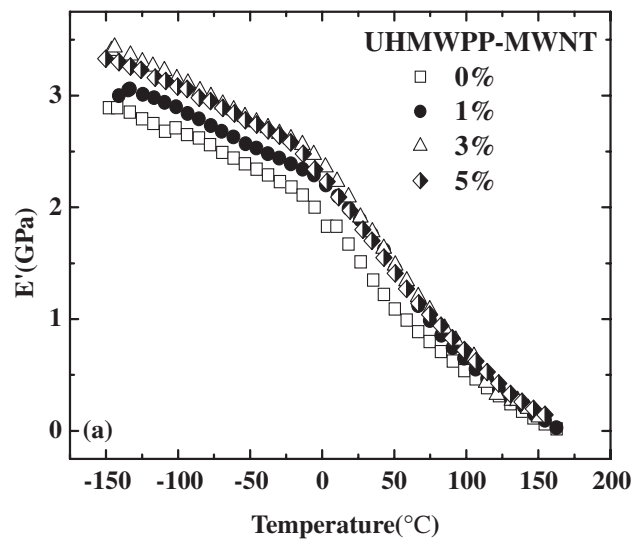

(b)

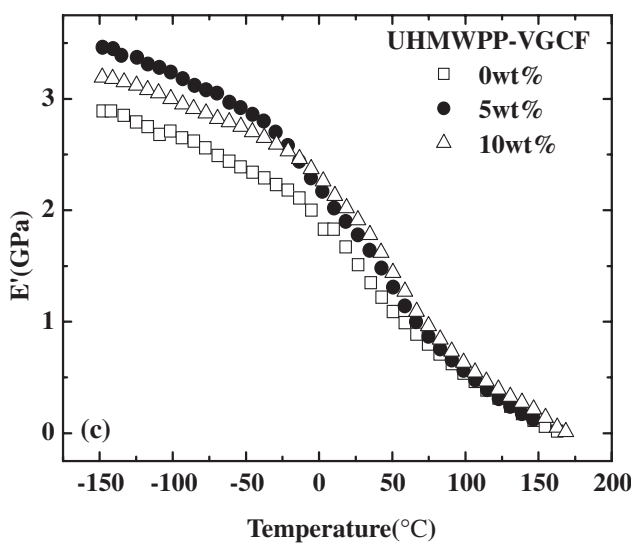

(c)

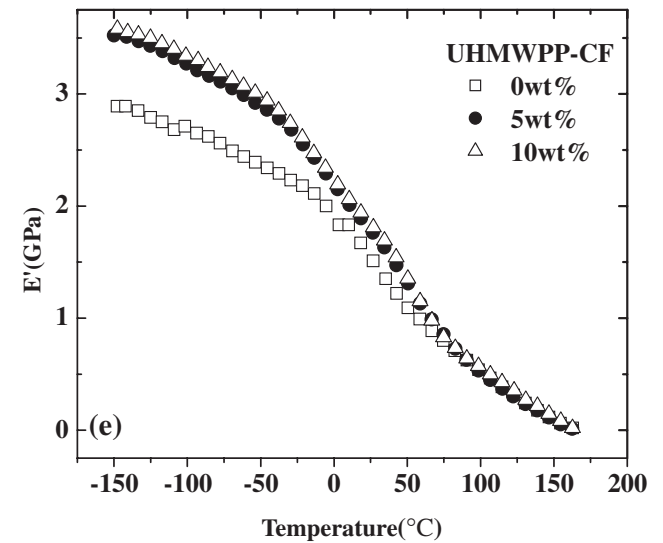

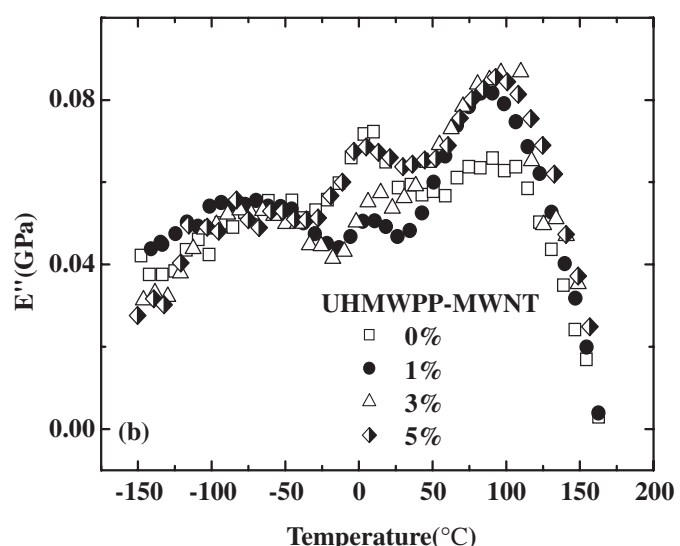
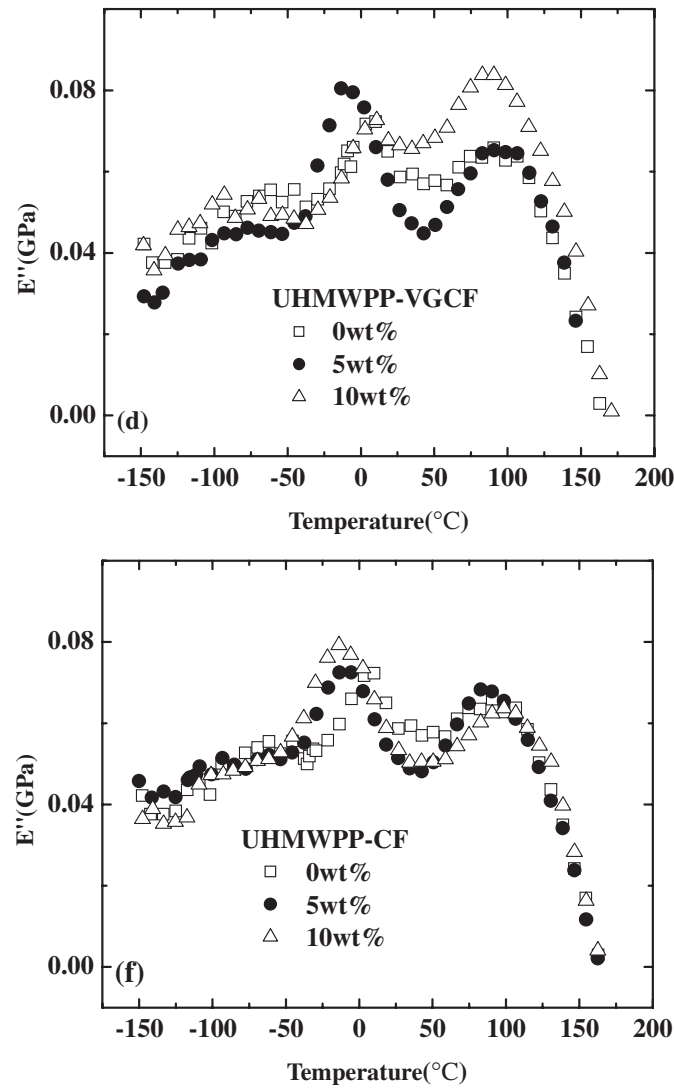

Figure 9. Temperature dependence of storage and loss moduli of the composites with the indicated filler contents. (a) UHMWPPMWNT, (b) UHMWPP-VGCF, (c) UHMWPP-CF.

lus increases with draw ratio $(\lambda)$. The value becomes higher with increasing VGCF contents for the composites with the same draw ratio. This means that VGCFs play an important role as reinforced fillers within the composite. In contrast, the increase in MWNT content beyond $3 \mathrm{wt} \%$ hampers an increase in Young's modulus and the values of Young's modulus are lower than those of the neat UHMWPP film with the same draw ratio. This is probably thought to be due to the poor dispersion of the MWNTs for the composites containing high loading as well as a number of entanglement points acting as obstacles to disturb smooth orientation of UHMWPP chains.

\section{Thermogravimetric Analysis}

Figure 10 shows thermal weight loss behavior against temperature by TG measured for UHMWPPMWNT, UHMWPP-VGCF and UHMWPP-CF composites and the corresponding derivative thermogravimetry (DTG). The weight $(\%)$ denotes ratio of the weight of the specimen at heating temperature to the original weight at room temperature. The temperature range used for the measurements is $30-650^{\circ} \mathrm{C}$ and the results in the range of $250-500^{\circ} \mathrm{C}$ are shown in this figure. The slight weight loss started at temperature above $c a .300^{\circ} \mathrm{C}$ for all the specimens and the drastic decrease occurred beyond $400^{\circ} \mathrm{C}$ and finished at $c a .470^{\circ} \mathrm{C}$. The initial drastic decomposition can be 

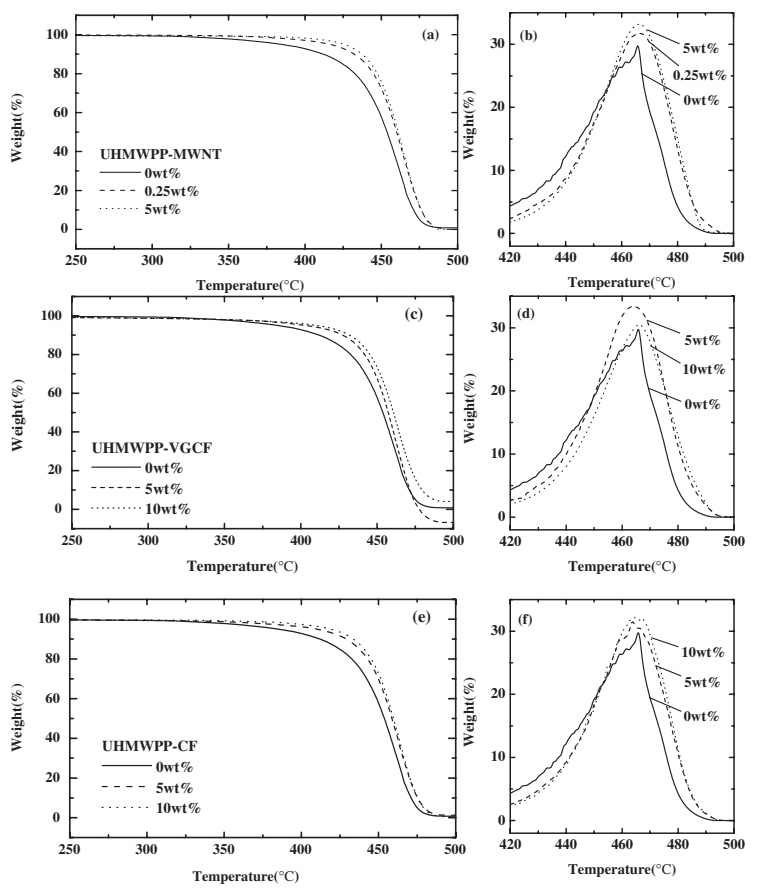

Figure 10. TG and DTG curves for the composites: (a) and (b) for UHMWPP-MWNT; (c) and (d) for UHMWPP-VGCF; (e) and (f) for UHMWPP-CF.

suppressed by the admixture of the fillers, indicating improvement of thermal stability of the composites.

The corresponding DTG curves gave the major peak at $465-467^{\circ} \mathrm{C}$, which indicates the degradation of saturated and unsaturated carbon atoms in itUHMWPP. By introducing the three kinds of filler, it was confirmed that each major peak appeared at the almost same temperature. This tendency was independent of amount of filler contents, which means that admixture of small amount of carbon fillers plays an important role to improve only thermal resistance of the initial decomposition.

\section{Electrical Conductivity}

Table III lists the electrical conductivity for the composite films in un-drawn state. The measurements were done by two-terminal and four-terminal methods. The values measured by the four-terminal method are one or two order higher than those by the two-terminal method. The estimation by the four-terminal method was limited for the composite whose conductivity is higher than $10^{-6} \mathrm{~S} / \mathrm{cm}$. The conductivity of the composite is very sensitive to their aspect ratios. For example, the addition of CFs causes no increase in electron conductivity, while the increase is the most significant for the addition of MWNTs. As shown in Figure 1, the CFs with the average diameter of $4.5 \mu \mathrm{m}$ have no entanglement points to form electrical channels, since very tough stiffness of the fibers cannot form flexible structure within the composite as
Table III. Electrical conductivity for UHMWPP, UHMWPPMWNT, UHMWPP-VGCF and UHMWPP-CF composites

\begin{tabular}{|c|c|c|c|}
\hline \multirow[b]{2}{*}{ Sample } & \multirow{2}{*}{$\begin{array}{l}\text { Filler } \\
\text { content } \\
(\mathrm{wt} \%)\end{array}$} & \multicolumn{2}{|c|}{ Electrical conductivity $(\mathrm{S} / \mathrm{cm})$} \\
\hline & & $\begin{array}{l}\text { Two terminal } \\
\text { method }\end{array}$ & $\begin{array}{c}\text { Four probe } \\
\text { method }\end{array}$ \\
\hline UHMWPP & 0 & $6.31 \times 10^{-13}$ & - \\
\hline \multirow[t]{3}{*}{ UHMWPP-MWNT } & 1 & $2.51 \times 10^{-11}$ & - \\
\hline & 3 & $5.37 \times 10^{-3}$ & $3.10 \times 10^{-2}$ \\
\hline & 5 & $8.51 \times 10^{-3}$ & $1.52 \times 10^{-1}$ \\
\hline \multirow[t]{2}{*}{ UHMWPP-VGCF } & 5 & $4.79 \times 10^{-6}$ & $1.48 \times 10^{-5}$ \\
\hline & 10 & $1.60 \times 10^{-4}$ & $1.99 \times 10^{-2}$ \\
\hline \multirow[t]{2}{*}{ UHWMPP-CF } & 5 & $9.12 \times 10^{-13}$ & - \\
\hline & 10 & $9.72 \times 10^{-13}$ & - \\
\hline
\end{tabular}

shown in Figure 5. The VGCFs have also the stiff structure but the average diameter of $150 \mathrm{~nm}$ is much thinner than the average diameter of CFs. Hence, it seems that the VGCFs with slight flexibility can form entanglement points within the composite locally, when a large amount of VGCFs are admixed in the UHMWPP matrix as shown in Figure 4. In contrast, the MWNTs with the highest aspect ratio have the most flexible structure and a number of electrical channel assuring high conductivity can be performed in the matrix (see Figure 6).

Figures $11 \mathrm{a}$ and $11 \mathrm{~b}$ show electric conductivity of UHMWPP-MWNT and UHMWPP-VGCF films, respectively, as a function of draw ratio $(\lambda)$. The measurements were done only by the two-terminal method, since the conductivities of most of the composites were less than $10^{-6} \mathrm{~S} / \mathrm{cm}$. The conductivity of UHMWPP-VGCF composite film decreased drastically with draw ratio. Namely, the $10 \%$ VGCF film became an insulator on stretching to $\lambda=5$. On the other hand, the UHMWPP-MWNT composite with $5 \mathrm{wt} \%$ MWNT content could not be stretched beyond $\lambda=15$ and then the results up to $3 \mathrm{wt} \%$ are represented. The decrease of conductivity for the UHMWPP-MWNT is very few at $\lambda=5$. But the elongation beyond $\lambda=5$ caused the gradual decrease in the conductivity and the value became less than $10^{-12} \mathrm{~S} / \mathrm{cm}$ beyond $\lambda=20$. This means that the number of entanglement points was maintained at $\lambda=$ 5 but decreased gradually with further elongation. Anyway, it is obvious that the large aspect ratio of the fillers is very important to suppress the decrease of electric conductivity by the elongation of the composite films.

\section{Differential Scanning Calorimetric Studies (DSC)}

To check thermal behavior of UHMWPP crystallites within the composites, DSC measurements were done for UHMWPP-VGCF, UHMWPP-CF and UHMWPP-MWNT composites, which are shown in 

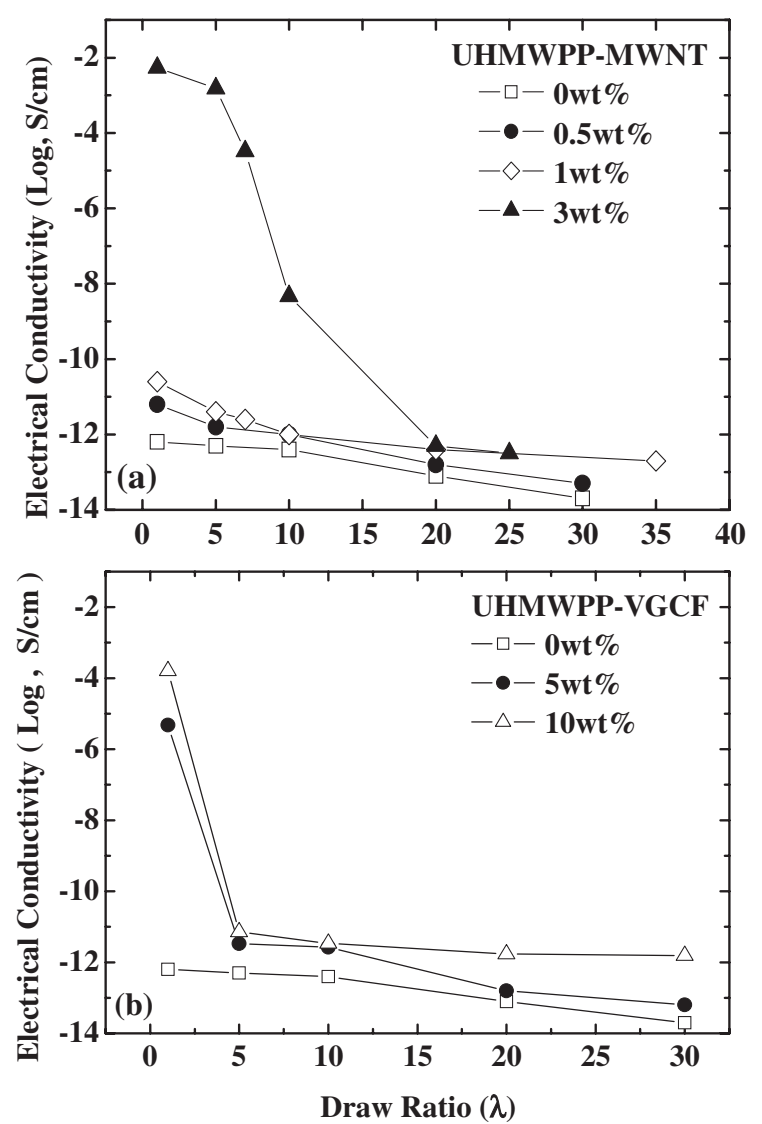

Figure 11. Electrical conductivity against draw ratio of the composites with the indicated contents (a) UHMWPP-MWNT and (b) UHMWPP-VGCF.

Figures $12 \mathrm{a}, 12 \mathrm{~b}$ and $12 \mathrm{c}$, respectively. The melting points of the composites are almost the same, independent of the kinds of filler and the content. The crystallinity calculated by eq 1 was $c a$. $63 \%$ for UHMWPP and $c a$. $67 \%$ for the composites, indicating a slight increase in crystallinity by the admixture of the three kinds of carbon filler. These results are in good agreement with the X-ray diffraction curves shown in Figure 7. The DSC curves indicate that UHMWPP crystallites were perfectly melted at $180^{\circ} \mathrm{C}$ but the corresponding diffraction peaks could be observed. This is due to the tension under X-ray measurement which retained sample shrinkage at temperatures close to the melting point. Namely, this phenomenon may be explained in terms of the concept that polymer chains hamper to take random coils and most of crystallites maintained lamellar structures associated with smaller entropy of fusion.

Moreover, LMWPP-carbon filler composites, which were prepared by kneading method at the melt state, have reported to provide interesting thermal crystallization behaviors. ${ }^{21,22}$ However, filler effect for thermal behavior has never been reported for UHMWPP. To study the shape dependence of the fillers on thermal properties of polymer matrix, the
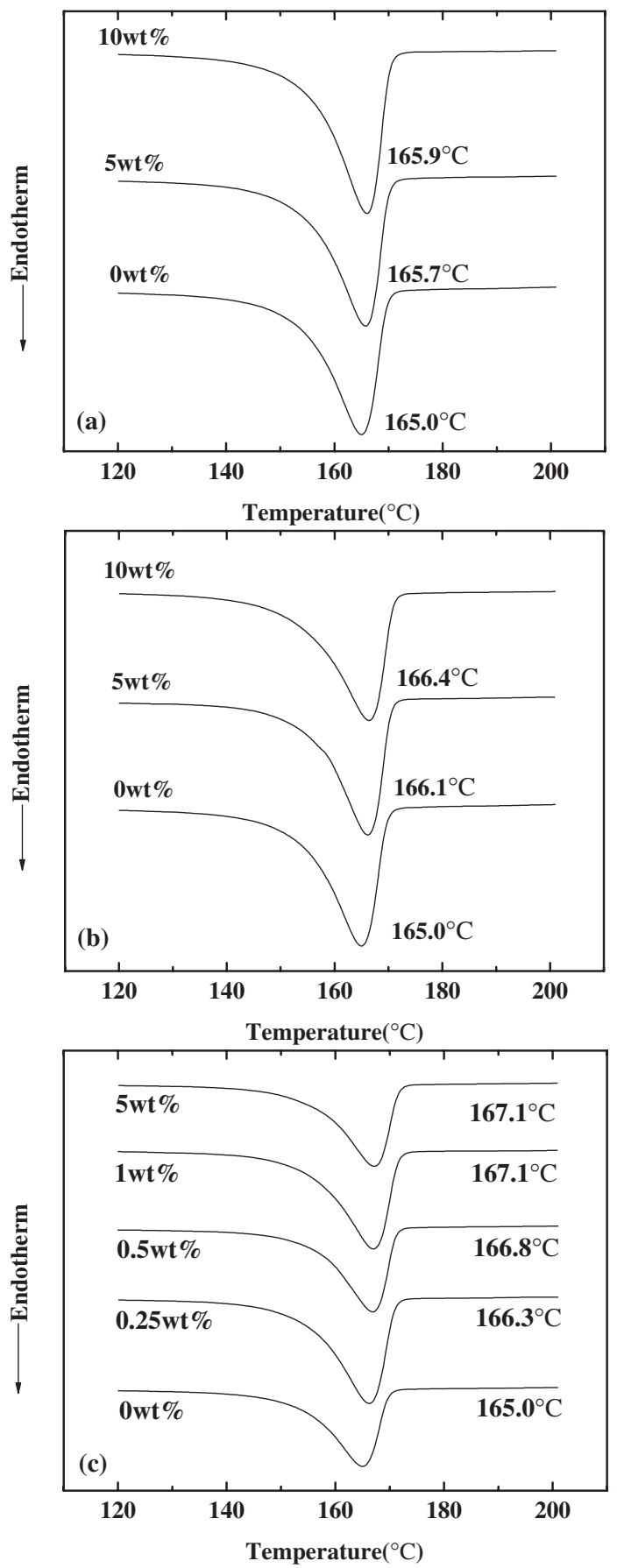

Figure 12. DSC curves of the composites with the indicated filler contents. (a) UHMWPP-VGCF, (b) UHMWPP-CF, (c) UHMWPP-MWNT.

UHMWPP dry gel films with complicated fibrous textures were heated up to $220^{\circ} \mathrm{C}$ at a scanning speed of $10^{\circ} \mathrm{C} / \mathrm{min}$ in order to obtain the melt film. This is an important technique, since the uniform mixing of UHMWPP powder and fillers was impossible by kneading even at $300^{\circ} \mathrm{C}$ corresponding to the starting temperature of decomposition of UHMWPP chains as shown in Figure 10, because of very high viscosity of UHMWPP. Namely, the melt films were obtained by the melting of gel films. 


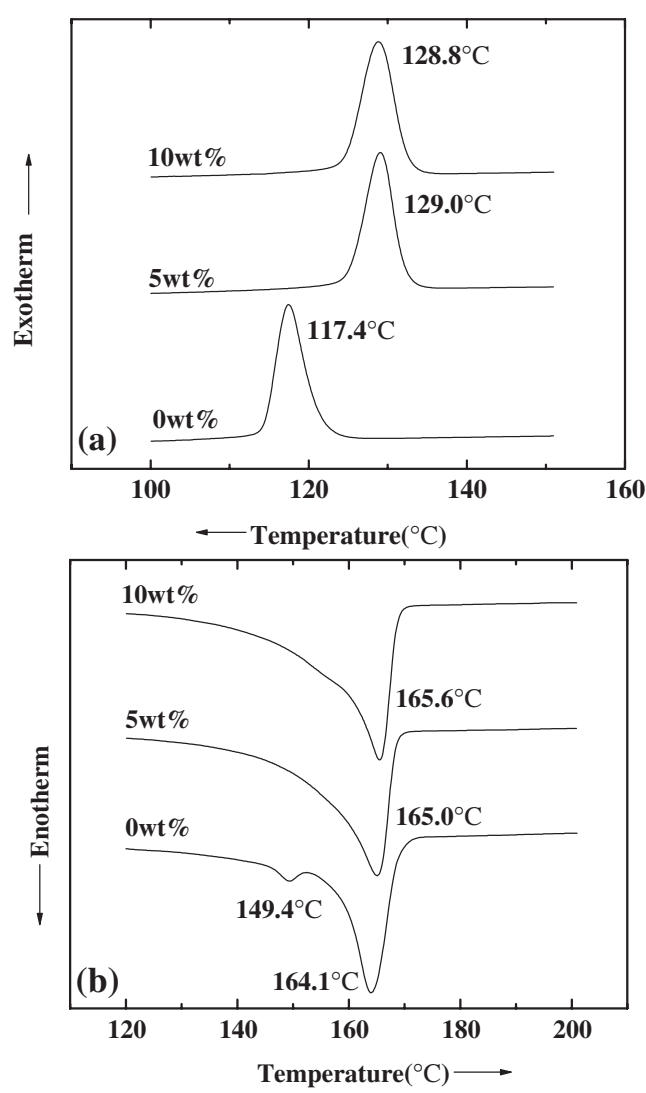

Figure 13. DSC curves of the UHMWPP-VGCF composites with the indicated VGCF contents under (a) the first cooling process and (b) the second heating process.

Figures $13 \mathrm{a}$ and $13 \mathrm{~b}$ show DSC curves for UHMWPP-VGCF films under the first cooling and the second heating processes. The initial heating was done up to $220^{\circ} \mathrm{C}$ at a speed of $10^{\circ} \mathrm{C} / \mathrm{min}$ as the first heating and subsequently the first cooling was done to room temperature at a speed of $5{ }^{\circ} \mathrm{C} / \mathrm{min}$. It is seen that the exothermic peak associated with crystallization appeared at $117.4{ }^{\circ} \mathrm{C}$ for the UHMWPP film and the peak shifted to higher temperature by admixing VGCFs. On the other hand, the endothermic peak associated with the melting point slightly shifted to higher temperature side. This means that VGCFs improve the rapid crystallization of UHMWPP and the resultant crystallites are slightly bigger and more stable. The same tendency was confirmed for the UHMWPP-CF composite as shown in Figure 14. Accordingly, the rapid crystallization and appearance of stable and big crystallites are obviously attributed to the admixture of carbon fillers. The beginning of the crystallization at lower temperature for the neat UHMWPP film suggests the production of unstable crystallites, which relates to the appearance of very small endothermic peak at $149.4^{\circ} \mathrm{C}$ under the second heating process. The peak obviously indicates melting of the unstable and small crystallites of UHMWPP in
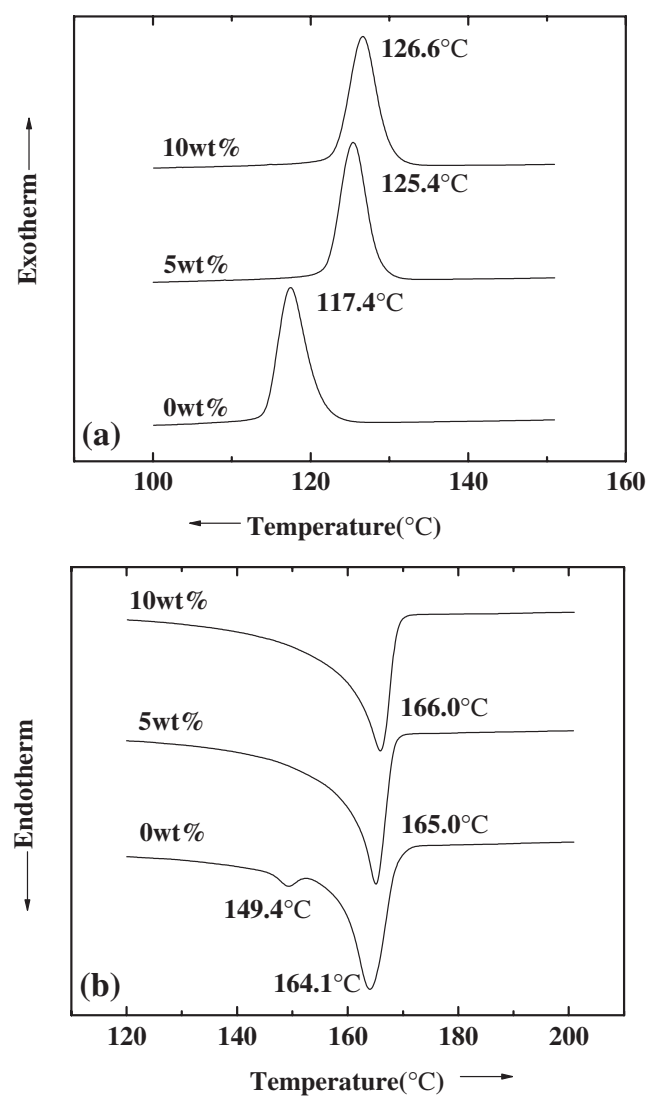

Figure 14. DSC curves of the UHMWPP-CF composites with the indicated $\mathrm{CF}$ contents under (a) the first cooling process and (b) the second heating process.

the films appeared under the cooling process. Unfortunately, the origin still remains an unresolved problem.

To obtain more conclusive evidence, the same measurement was carried out for UHMWPP-MWNT composites as a function of MWNT content. Figure 15 shows the results. The exothermic peak shifted to higher temperature, as the MWNT content increased. At $5 \mathrm{wt} \%$ MWNT, the peak appeared at $133.6^{\circ} \mathrm{C}$, which is the highest crystallization temperature among the composites containing $10 \mathrm{wt} \% \mathrm{VGCF}$ and $10 \mathrm{wt} \% \mathrm{CF}$ (see Figures 13 and 14). This means that the crystallization of UHMWPP is sensitive to their average aspect ratio of fillers. Unfortunately, it was impossible to recognize the change in morphology of the composite films by SEM under the heating and cooling cycle. Nevertheless, it is evident that the addition of carbon fillers with very high average aspect ratio provided stable and big UHMWPP crystallites. The DSC curves in Figures 13, 14 and 15 showing the melting point higher than that of LMWPP indicate that the thermal property of the UHMWPP-filler composites prepared by gelation/crystallization was much better than that of LMWPP. ${ }^{22}$

Table IV summarizes crystallization point, melting point and crystallinity of the composites during the 
X. JIANG et al.

Table IV. Thermal properties of neat UHMWPP and UHMWPP-filler

\begin{tabular}{lcccccc}
\hline \multirow{1}{*}{ Sample } & $\begin{array}{c}\text { Filler } \\
\text { content } \\
(\mathrm{wt} \%)\end{array}$ & $T_{\mathrm{c}}\left({ }^{\circ} \mathrm{C}\right)$ & $\Delta H_{\mathrm{c}}(\mathrm{J} / \mathrm{g})$ & $T_{\mathrm{m}}\left({ }^{\circ} \mathrm{C}\right)$ & $\Delta H_{\mathrm{f}}(\mathrm{J} / \mathrm{g})$ & $\mathrm{X}_{\mathrm{c}}(\%)$ \\
\hline UHMWPP & 0 & 117.1 & 105.00 & 165.6 & 107.00 & 56.32 \\
\hline UHMWPP-MWNT & 0.25 & 126.1 & 117.29 & 165.9 & 119.30 & 62.79 \\
& 0.5 & 126.8 & 119.60 & 165.8 & 122.61 & 64.53 \\
& 1 & 128.4 & 118.18 & 166.1 & 123.23 & 64.86 \\
& 3 & 130.9 & 113.40 & 159.3 & 125.77 & 66.19 \\
& 5 & 133.6 & 125.26 & 166.8 & 131.58 & 69.25 \\
\hline UHMWPP-VGCF & 5 & 129.0 & 106.32 & 165.0 & 109.47 & 57.62 \\
& 10 & 128.8 & 120.00 & 165.6 & 120.00 & 63.16 \\
\hline UHWMPP-CF & 5 & 125.4 & 111.58 & 165.0 & 110.53 & 58.73 \\
& 10 & 126.6 & 110.67 & 166.0 & 113.33 & 58.25 \\
\hline
\end{tabular}
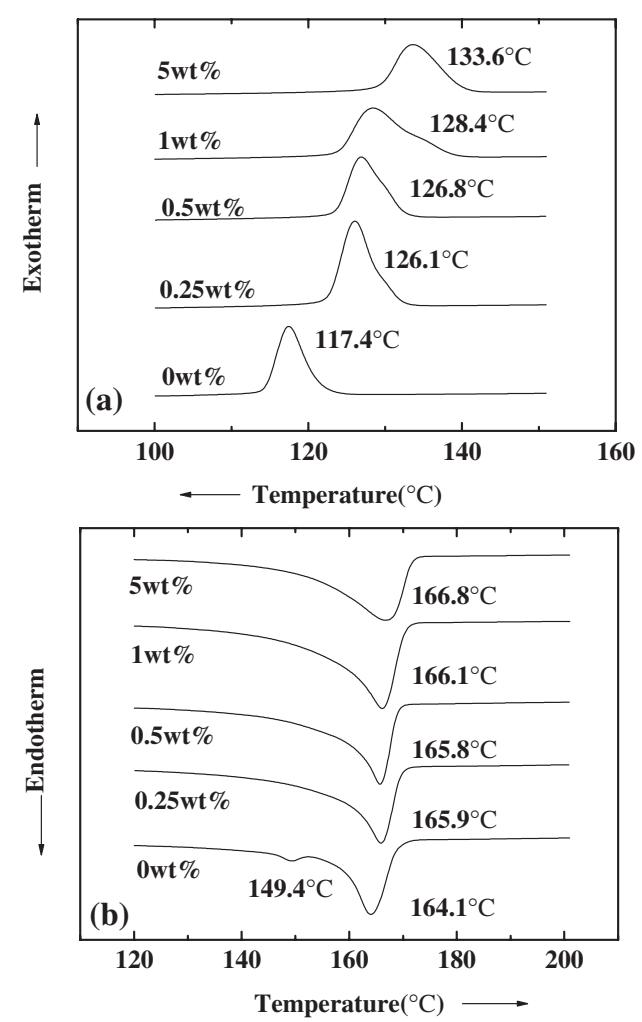

Figure 15. DSC curves of the UHMWPP-MWNT composites with the indicated MWNT contents under (a) the first cooling process and (b) the second heating process.

cooling and second heating stages. The increase in crystallinity is confirmed for the admixture of the fillers and this tendency was the most significant for the MWNTs. Especially, the crystallinity of the composite with 5 wt \% MWNT is $c a .13$ and 6\% higher than that of the neat UHMWPP melt film and that of the UHMWPP-VGCF composite with $10 \mathrm{wt} \%$ VGCF content, respectively. Such thermal behavior indicates further application of UHMWPP-carbon fillers to the industrial field and the effect is thought to be more significant as the aspect ratio of fillers increases.

\section{CONCLUSIONS}

UHMWPP $\left(M_{v}=5.4 \times 10^{6}\right)$ composites filled with MWNTs, VGCFs and CFs were prepared by gelation/ crystallization from solution, in which their aspect ratio of MWNTs, VGCFs and CFs were 500-1000, 50300 and 5-20, respectively. The thermal, electrical and mechanical properties of these composites were studied in terms of their aspect ratios by using TG, DSC, SEM, WAXD and dynamic visco-elastic measurements. The elongation up to 30 times could be achieved for the composite films with $10 \mathrm{wt} \%$ VGCF, while the maximum draw ratio of the UHMWPPMWNT composite with $3 \mathrm{wt} \%$ MWNT was 25 times. Under SEM observations, a number of entanglement points were confirmed in UHMWPP-MWNT films, which was attributed to the high aspect ratio of MWNTs assuring the considerable flexibility. The electric conductivity was the highest for the UHMWPP-MWNT composite and the decrease of the conductivity by elongation of the composite film was less pronounced, when the filler content was the same. Actually, for the UHMWPP-VGCF films, the conductivity decreased drastically even at 5 times. On the other hand, a large number of entanglement points of MWNTs were thought to be maintained in the composites with the draw ratios lower than 5 times to keep the high conductivity. Furthermore, an interesting phenomenon for the thermal properties was confirmed for the melt films. The melt films were prepared by melting the original dry gel film at $220^{\circ} \mathrm{C}$, since the kneading method was impossible to prepare the composite because of very high viscosity of UHMWPP. The resultant melt film provided an interesting thermal behavior. For the composite films, the exothermic peak under cooling process appeared at higher temperature side and the endothermic peak by heating process shifted to higher temperature indicating that the crystallites became bigger and more 
stable, since the three kinds of filler can act as nucleation sites. This tendency was more pronounced by admixing the MWNTs with the highest aspect ratio. This indicated that the fillers with high aspect ratio play an important role to produce reinforce materials with high electric conductivity and good thermal property.

\section{REFERENCES}

1. S. Kumar, H. Doshi, M. Srinivasarao, J. O. Park, and D. A. Schiraldi, Polymer, 43, 1701 (2002).

2. S. A. Gordeyev, J. A. Ferreira, C. A. Bernardo, and I. M. Ward, Mater. Lett., 51, 32 (2001).

3. C. F. Ou, Eur. Polym. J., 38, 467 (2002).

4. E. Assouline, A. Lustiger, A. H. Barber, C. A. Cooper, E. Klein, and E. Wachtel, J. Polym. Sci., Part B: Polym. Phys., 41, 520 (2003).

5. S. Subramoney, Electrochem. Soc. Interface, 18, 34 (1999).

6. J. I. Paredes, A. Martínez-Alonso, and J. M. D. Tascón, Carbon, 39, 1575 (2001).

7. M. Endo, Y. A. Kim, T. Hayashi, K. Nishimura, T. Matusita, and K. Miyashita, Carbon, 39, 1287 (2001).

8. D. D. L. Chung, Carbon, 39, 1119 (2001).

9. C. J. Lee and J. Park, Carbon, 39, 1891 (2001).

10. R. Maragoni, P. Serp, R. Feuer, Y. Kihn, P. Kalck, and C. Vahlas, Carbon, 39, 443 (2001).

11. L. Ci, B. Wie, J. Liang, J. Liang, C. L. Xu, and D. H. Wu, Carbon, 39, 329 (2001).

12. K. Lozano and E. V. Barrera, J. Appl. Polym. Sci., 79, 125 (2001).

13. R. Andrews, D. Jacques, A. M. Rao, T. Rantell, F. Derbyshire, and Y. Chen, Appl. Phys. Lett., 75, 1329 (1999).

14. F. W. J. Hattum, C. A. Bernardo, J. C. Finegan, G. G. Tibbetts, R. L. Alig, and M. L. Lake, Polym. Compos., 20,
683 (1999).

15. D. Qian, E. C. Dickey, R. Andrews, and T. Rantell, Appl. Phys. Lett., 76, 2868 (2000).

16. M. S. P. Shaffer and A. H. Windle, Adv. Mater, 11, 937 (1999).

17. R. Haggenmueller, H. H. Gommans, A. G. Rinzler, J. E. Fischer, and K. I. Winey, Chem. Phys. Lett., 330, 219 (2000).

18. L. Jin, C. Bower, and O. Zhou, Appl. Phys. Lett., 73, 1197 (1998).

19. J. Dupire and J. Michel, Fina Research SA., European patent 1,054,036 AL, 2000.

20. L. Valentini, J. Biagiotti, J. M. Kenny, and S. Santucci, Compos. Sci. Technol., 63, 1149 (2003).

21. A. Amash and P. Zugenmaier, J. Appl. Polym. Sci., 63, 1143 (1997).

22. M. A. López Manchado, L. Valentin, J. Biagiotti, and J. M. Kenny, Carbon, 43, 1499 (2005).

23. M. Matsuo, C. Sawatari, and T. Nakano, Polym. J., 18, 759 (1986).

24. C. Sawatari and M. Matsuo, Macromolecules, 22, 2968 (1989).

25. D. S. Bethune, Phs. Rev. B: Condens. Matter, 323, 90 (2002).

26. E. Borowiak-Palen, T. Pichler, X. Liu, M. Knupfer, A. Graff, and O. Jost, Chem. Phys. Lett., 363, 567 (2002).

27. G. Natta and P. Corradini, Nuovo Cimento Suppl., 15, 40 (1960).

28. G. Natta, Macomol. Chem., 35, 94 (1960).

29. J. A. Sauer, D. R. Morrow, and G. C. Richardson, J. Appl. Phys. 36, 3017 (1965).

30. M. Kojima, J. Polym. Sci., Part A-2, 5, 597 (1967).

31. N. G. McCrum, B. E. Read, and G. Williams, "Anelastic and dielectric effects in polymeric solids," John Wiley and Sons, London, 1967. 